\title{
Another significant moment in Canadian gastroenterology
}

C ANADIAN GASTROENTEROLOGY HAS HAD MANY SIGnificant moments: the establishment of the Canadian Association of Gastroenterology; the establishment of the Canadian Association for the Study of the Liver; the Canadian participation in multicentre studies; the establishment of GI Research Fellowships; the enthusiastic, well focused but unfortunately unsuccessful bids for the World Congress of Gastroenterology; Dr Claude Roy's receipt of the Order of Canada; the establishment of the Digestive Diseases Foundation; the initiation of the Postgraduate Fellows' Course in Gastroenterology; five years of successful publication of The Canadian Journal of Gastroenterology; and now the first Canadian multi-authored English and French language textbook on gastroenterology, published in October 1992.

It was 100 years ago that Sir William Osler published the first Canadian textbook of medicine, so this 100 year anniversary is auspicious for this significant moment in Canadian gastroenterology. This multi-authored textbook was prepared from contributors across this great and notwithstanding united country, who have provided a textbook suitable for all of us interested in this subspecialty. There are unique sections ranging from signs and symptoms, to nutrition, to ethical issues, to considerations of the importance of clinical trials, to organ and system based approaches to common problems. The learning objectives which have been suggested are those used at the University of Alberta, but this very process has provided a national focus so that undergraduate and postgraduate training directors across the country can discuss and focus upon the evolution of these objectives for the second edition of this book.

The editors wish to say a special word of thanks to Astra Canada for their corporate sponsorship and to extend a special word of thanks to Mr Peter Dixon for his tireless efforts, interest and enthusiasm to provide the means to ensure that this book is made available to senior undergraduate medical students, gastroenterology training fellows, and to members of the Canadian Association of Gastroenterology. A special word of note of praise goes as well to the force which these sponsors had in enthusiastically agreeing to have this book appear in both English and in French, recognizing the Canadian reality and appreciating how important it would be for the Canadian effort to be truly Canadian in tone and in tongue. So, this is truly the first Canadian multi-authored textbook in gastroenterology, and the first French Canadian textbook in the same token. Indeed, while the material was in the process of being translated (some parts from French to English, other parts from English to French), it was clear that some of the English expressions which we use in common place language are unclear. Indeed, it was in recognition of the two Canadian realities, the two Canadian languages, that greater clarity and understanding was possible.

For those of you who wish to obtain a copy of this book, you are asked to kindly refer to the notice which appears in this issue of the Journal (page 376).

Like a sonnet or a song, each rendition of a textbook needs to evolve to serve the needs of its audience, and its users. It was difficult to strike a balance between the very small 'stick in your back pocket' manual versus a $50 \mathrm{lb}$ encyclopedia (costing 100s of dollars). To all of the contributors, the editors would like to extend their many thanks and notes of appreciation. For those of you already sharpening your pencils and beginning to think about Volume II, please remember your deadline!

ABR Thomson, MD, FRCPC, FACC University of Alberta, Edmonton, Alberta EA Shaffer, MD, FRCPC, FACP University of Calgary, Calgary, Alberta A Archambault, MD, FRCPC University of Montreal, Montreal, Quebec 


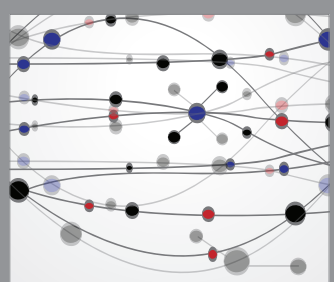

The Scientific World Journal
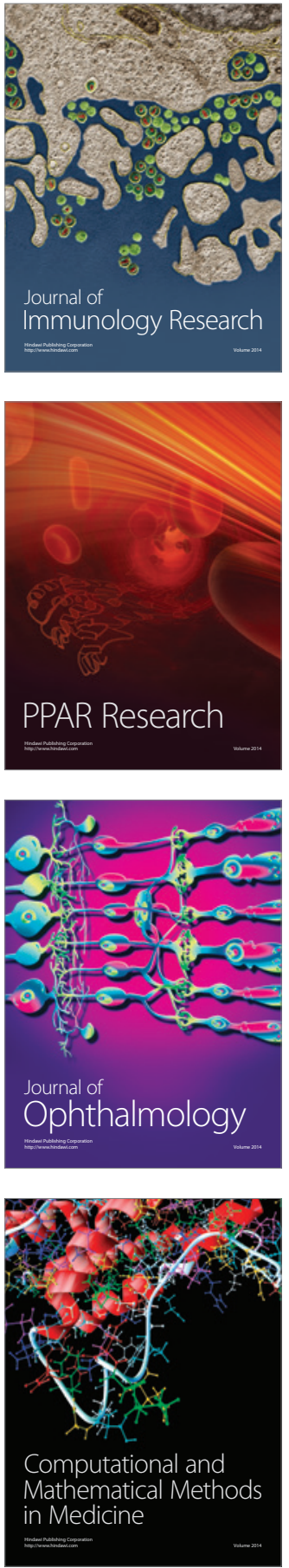

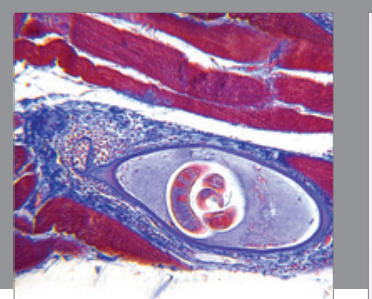

Gastroenterology Research and Practice

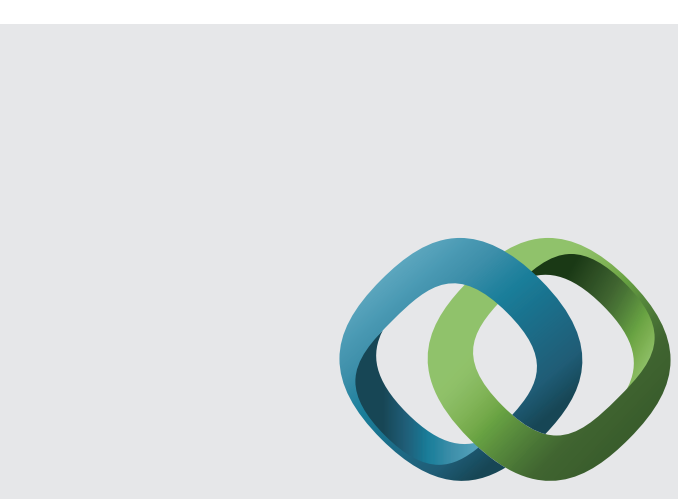

\section{Hindawi}

Submit your manuscripts at

http://www.hindawi.com
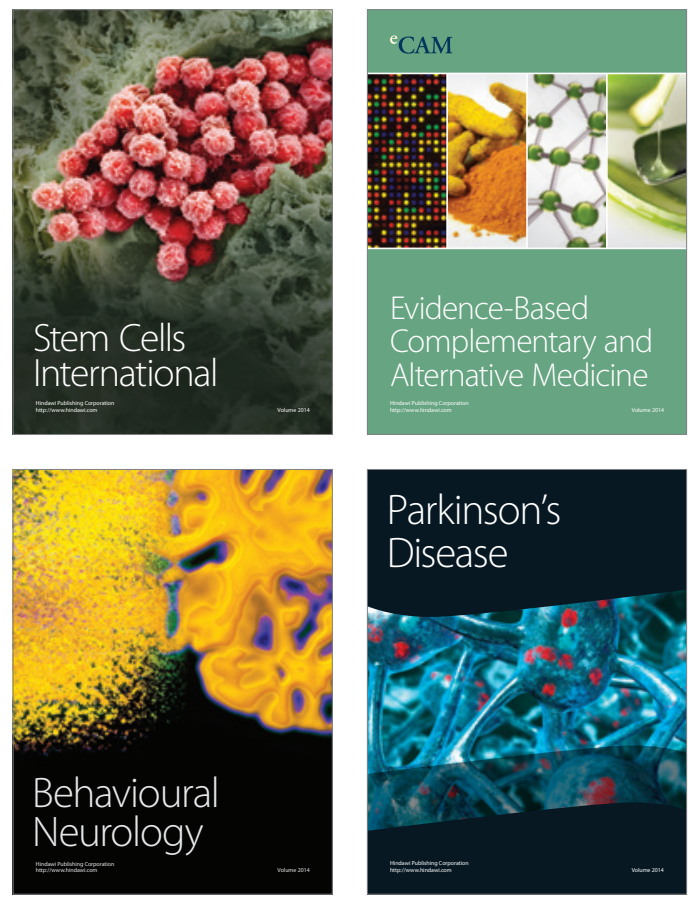
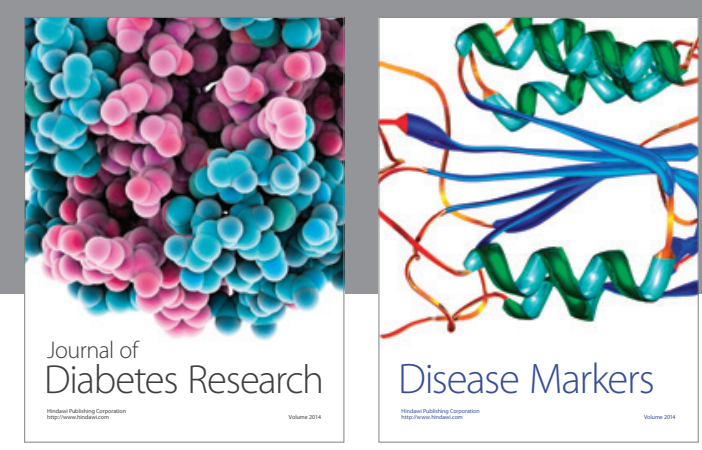

Disease Markers
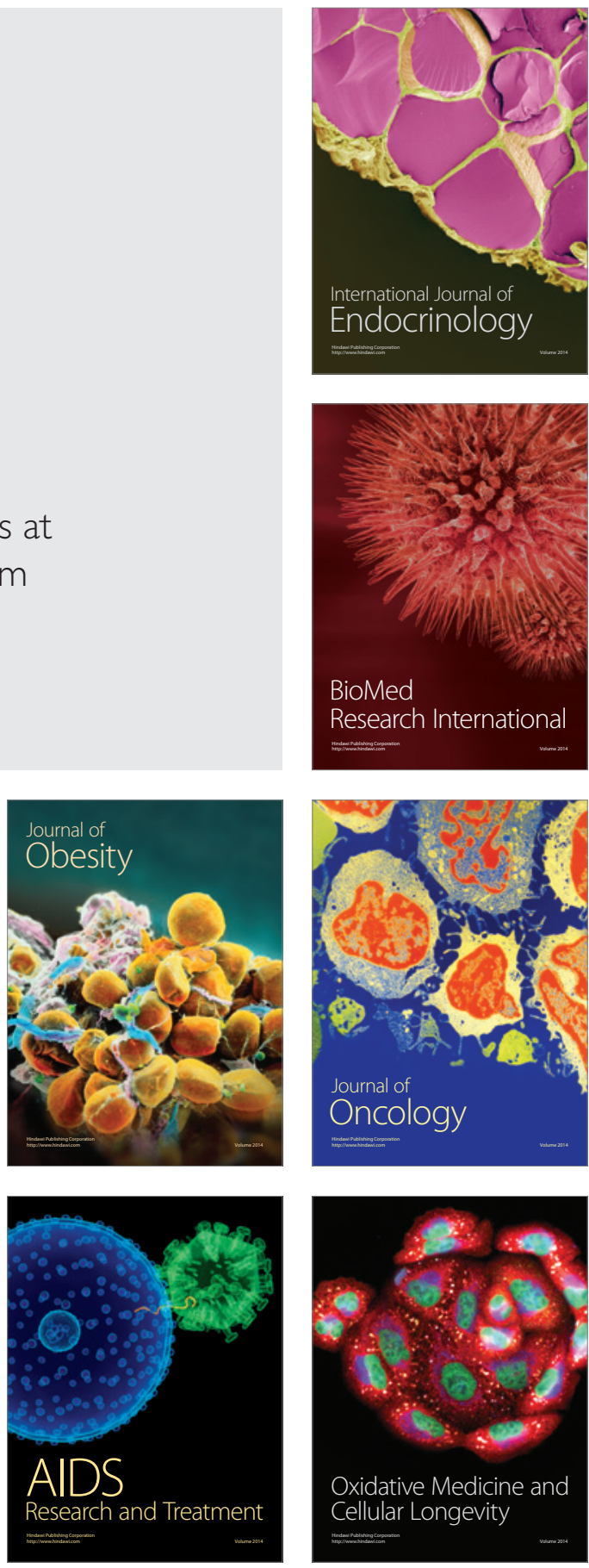